\title{
The Design and Implementation of Family Energy Management System
}

\author{
Luhua Zhang, Wei Song, Hengchun Ding, Zhonglin Yi and Ruiming Yuan \\ Jibei Electric Power Company Limited Metering Centre, Beijing 102208, China
}

\begin{abstract}
Based on the construction of intelligent electrical pilot in the state grid corporation of China, fully grasp the requirements of intelligent power demand management, intelligent network based on the research of smart grid-oriented Advanced Metering Infrastructure (AMI), we design and realize the family comprehensive energy management system for the power users. Based on the family network which is composed of smart meters, intelligent terminals, intelligent sockets and other smart devices, the system can access and measure distributed power sources and electric cars, monitor the comprehensive energy consumption and optimize the family energy management, realize intelligent control of household appliances and the two-way interaction with users. AMI system provides powerful technical support for the construction of new interactive relationship in which energy information and traffic flows real-timely between company and customers, and meet the demand of the advanced technology, economic efficiency, flexible and diverse services, the requirements of opening, friendly to actively development.
\end{abstract}

Keywords-AMI; intelligent power; family energy management; two-way interaction

\section{INTRODUCTION}

In order to adapt to the needs of socio-economic development, fully support the development of clean energy and low-carbon economy, ensure the secure, economic and efficient and sustainable power supply, improve the quality of power supply and service level, based on the significant breakthrough in UHV transmission and previous research, combined with the new trend and the actual situation of Chinese power grid, the state grid corporation actively promote the development and innovation of grid technology, start the research of the strong smart grid[1].

From the perspective of international situation, the construction of smart grid is in the initial stage[2]., but it represents the development trend of future power industry, is an important part of the new energy technology revolution. It is possible to become a new power industry leader and occupy the favorable position in the future for the country which grasp the core technology of smart grid. Therefore, the development of smart grid provides a historical opportunity for us to realize the leaping development and build a world-class power grid in China. From the perspective of domestic situation in China, the problems of safety, efficiency and environment for the energy industry development become more and more outstanding. Through the construction of smart grid, we will change the mode of development, transmission and utilization of energy, thus realize the sustainable development of the energy industry.
Based on the energy distribution and power industry development in our country, to promote the new energy revolution and construct the strong smart grid which contains all the parts and all the voltage levels in the power system has become the new development trend of power grid in China.

This paper introduces the research of smart grid in North China Grid Company limited. On the basis of the requirements of power demand management and the research of AMI facing the smart grid, we design and realize the intelligent energy management system in the family, based on the description of intelligent system which contains smart meter, intelligent interactive terminals and intelligent socket etc, the system provides a friendly two-way interaction for the grid companies and power users, satisfies the requirement of marketing management and customer service.

\section{DRIVING FACTORS}

As the user's service demands and energy utilization form changing, power users are changing from passive participants to active participants in the value chain, and have higher requirement to the service level of grid companies[3].

This is the objective law of the development of the power grid that users change from passive participants to active participants. User's requirements of service and demand will also change. With the ladder and peak prices carrying out, users will get more incentive, be more sensitive to the electricity costs and change their power behavior. Users hope to get more timely and accurate information, raise their requirements to the grid company's service level. To improve energy efficiency and environmental protection will gradually become an important power demand side of behavior.

In addition, with the change of the user's energy utilization mode, household electric cars and distributed power generation will be more access to the power grid, and will influence the grid operation, such as: two-way tide problem the extra energy which generated by the distributed power generation access to power grid, Electric cars need to increase the bearing capacity and lead to serious peak power problems, the problem of load curve change caused by distributed power generation, demand response and electric car[4].

Therefore, the direction of the future development of the intelligent power is to construct the friendly and interactive smart grid, provide the timely and accurate information, realize the user's choices by himself, satisfy the diversified demand of the user, promote the service quality of the grid company[5].

North China Grid Company limited pay much attention to the construction of the smart grid, early 2009, the company 
launched the construction of smart grid comprehensively, and start the research of Advanced Metering Infrastructure (AMI) in March. According to the development strategy of building strong smart grid in the state grid corporation and the requirements of "unified planning, unified standard, unified construction", the company undertake the construction task of the experimental intelligent power community, and become the first pilot unit of the construction of power information acquisition system.

The most important thing of the construction of smart grid is that we must actively carry out the research of relevant technology of the experimental intelligent power community, meet the requirement of the advanced technology, economic efficiency, flexible and diverse services, and the requirements of opening, friendly to actively development.

\section{FAMILY COMPREHENSIVE ENERGY MANAGEMENT SYSTEM}

\section{A. Overview}

Family comprehensive energy management system facing to the intelligent power is an important component of Advanced Metering Infrastructure (AMI), and positive exploration of the intelligent family. The family comprehensive energy management system uses advanced measurement, efficiency control, high speed communications, rapid storage technology to build strong marketing support platform and two-way interactive platform, to realize the intellectualized marketing business and modernized marketing management.

\section{B. Overall Design of the Family Comprehensive Energy Management System}

The family comprehensive energy management system is an intelligent network system which base on digital and network technology, rely on the Advanced Metering Infrastructure (AMI) and be the integration of domestic digital equipments. These domestic digital equipments, including digital information equipment, household appliances, safety monitoring equipment etc, which got together by the wire or wireless way, provide the safe, reliable and intelligent services for power users. Based on AMI, the intelligent family comprehensive energy management system has the following features:

(1) Provide abundant energy information. Through the reliable communication network, the users can easily get all kinds of the energy consumption informations, can master the situation of energy consumption in the family, including electricity information, distributing power information, household appliances information, water/gas/heat consumption information, etc. (2)Have strong controllability. Through the interaction portal which constituted by the smart meters and smart display terminals, household electrical equipment can be in touch with telecommunication terminal (mobile phones, computers, etc), then the users can realize to control the household electrical equipment remotely, thus can improve the quality of life. (3)Support the expandable financial services. People have more and more accepted the financial management and consumption indoors, in the intelligent family with AMI, the users can realize prepaid operation indoors. Through the reliable communication network which constituted by the smart meters and intelligent display terminals, can realize auxiliary economic transaction, enjoy the value-added services provided by power companies. (4) Distributed energy access. The use of renewable and distributed energy in the intelligent family reflects life idea of saving and environmental protection. Users can get profit by installing distributed energy, can realize the demand responses with power companies by using the storage devices, can realize despicking and padding valley, can improve the power distribution reliability, and achieve the double harvest of social benefit and economic benefit.

\section{Functional Design of the Main Equipments}

The family comprehensive energy management system is the basis of demand side management. In the system, the home network which is constituted by smart meters, intelligent terminals and intelligent socket etc, can support the distributed energy, electric cars to access and measure, can realize household appliances controlling, household energy consumption monitoring and energy management etc. the functional design of the main equipments as follow:

\section{1) Smart Meter}

The single-phase smart meter and auxiliary equipments which is developed independently is the core of senior measurement and control in the family energy management system.

The technical characteristics of smart meter are including:

(1) The two-way and wide measuring range technology, 5-80A (16 times) measuring range , two-way active power and four-quadrant reactive power measurement.

(2) Achieve voltage, current, power factor and power quality real-time monitoring.

(3) Internally install big-power magnetic relay, support distant switching-in/off, to realize the requirement of cut-off for smart meter prepaid management.

(4) Smart meter support rates, complex rates and multistep electrovalence.

(5) Have the heating-plug communication modules. The ascending communication station has four communication modes: MCWILL, PLC, GPRS and RF. We can realize the two-way communication with smart terminals and smart hand-held terminals by RF, RS485, infrared system etc. The system supports other communication technology, and has the automatic identification function when the module is replaced. Through the smart meters which have the features of high-precision, wide-ranged and big load breaking capacity, we can realize the two-way active power and four-quadrant reactive power metering, demand measurement, multistep electrovalence, the rate and the time step, freezing, prepaid function, parameter setting, event record and report, telecommunication, local communication, data acquisition and storage, programming, electricity charging, power quality monitoring and analysis, remote and local control and so on, 
can satisfy the requirements of intelligent power measurement and control.

\section{2) Smart Terminal}

The smart display terminal which is developed independently is the interactive portal of the family comprehensive energy management system. The management system based on smart terminal has the following characteristics:

(1) In the grid companies, smart display terminal can communicate with Smart meter and smart hand-held terminal by RS485 or RF. And indoors, it can communicate with intelligent socket and water/gas meters by RF.

(2) The users can easily master the situation of energy consumption in the family, including electricity information, distributing power information, household appliances information, water/gas/heat consumption information, etc.

(3) Through the interaction portal which constituted by the smart meters and smart display terminals, household electrical equipment can be in touch with telecommunication terminal (mobile phones, computers, etc), then the users can realize to control the household electrical equipment remotely, thus can improve the quality of life.

(4)The users can realize prepaid operation indoors.

As the interactive portal of the users and grid companies, smart display terminal can read, report and display the energy consumption of electricity, water, gas in the family, can report the information of fault and maintenance, can receive and show the announcements which are issued by the master station, etc. With these functions, AMI realizes the two-way interaction. Based on the wireless intelligent socket, AMI system can realize to monitor and control the household appliances, and guide the users saving power.

\section{3) Distributed Energy Access}

According to the definition of the distributed energy alliance, distributed energy is all kinds of products and technologies that applied in the user side independently, including: combined heat and power generation, distributed renewable energy, such as solar power systems, etc. The significance is to improve energy efficiency and reduce energy losses, reduce energy cost, reduce carbon dioxide emissions, etc.

This system uses solar power system, the family management system can realize real-time data acquisition, timing automatic data collection and copy, showing the current/day/month data information and access status messages of the distributed energy, etc.

\section{CONCLUSION}

Smart display terminal and smart meter constitute the interactive portal for electric users and company. Smart display terminal can read, report and display the energy consumption of electricity, water, gas in the family, can report the information of fault and maintenance, can receive and show the announcements which are issued by the master station, etc.
With these functions, AMI realizes the two-way interaction. Based on the wireless intelligent socket, AMI system can realize to monitor and control the household appliances, and guide the users saving power. By the network of smart meter-display terminal- intelligent socket, electric users can use Internet or mobile phone to monitor the household appliances remotely. There is radio frequency device in the smart display terminal, enables users to realize prepaid operation indoors.

The family comprehensive energy management system which we designed, provides important technical support and direction to the construction of smart grid in the North China Grid Company limited, deepens the technology implementation program of intelligent power, enriches the connotation and the technology implementation program of AMI system, provides important reference for the construction of intelligent power.

\section{REFERENCES}

[1] YU Yixin , LUAN Wen peng. Smart grid. Power System and Clean Energy, 2009, 25( 1) : 7-11

[2] European Comm ission. European smart grids technology

[3] platform: vision and strategy for Europe's electricity networks of the future [ E B/ OL ] . [ 2008-10-10].

[4] HAS SE P. Int ell iGrid: a smart n etw ork of pow er. EPRIJournal, 2005: 17- 25

[5] XIAO Shijie. Consideration of technology for constructing Chinese smart grid. Automation of ElectricPower Systems , 2009, 33( 9) : 1-4

[6] WU Jiandong. Innovative development of smart grid and interactive smart grid in China. Power System and Clean Energy, 2009, 25(4) : 5- 8. 